
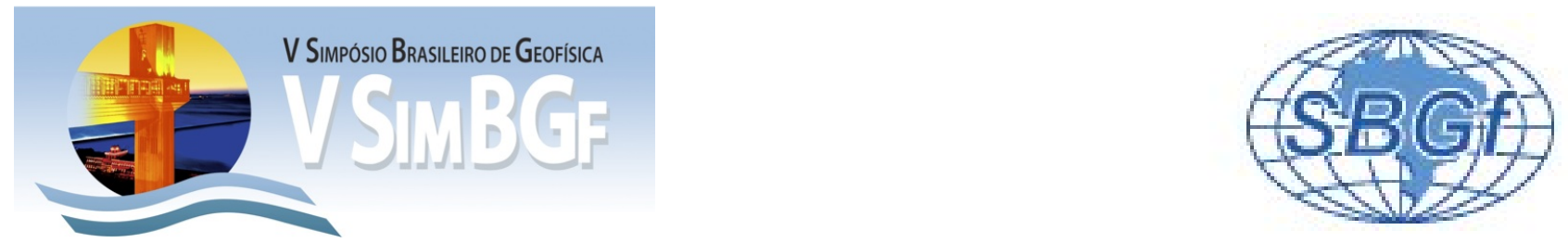

\title{
Imageamento de diffrações no domínio do tempo usando trajetórias para continuação do afastamento(OCO)
}

\author{
Diffraction imaging in the time domain using offset continuation (OCO) trajec- \\ tories
}

Tiago A. Coimbra*(IMECC-UNICAMP), J.J.S. de Figueiredo (IG-UFPA \& INCT-GP), Amélia Novais (IMECCUNICAMP \& INCT-GP) and Jörg Schleicher (IMECC-UNICAMP \& INCT-GP)

\begin{abstract}
Copyright 2012, SBGf - Sociedade Brasileira de Geofísica Este texto foi preparado para a apresentação no $V$ Simpósio Brasileiro de Geofísica, Salvador, 27 a 29 de novembro de 2012. Seu conteúdo foi revisado pelo Comitê Técnico do $V$ SimBGf, mas não necessariamente representa a opinião da SBGf ou de seus associados. É proibida a reprodução total ou parcial deste material para propósitos comerciais sem prévia autorização da SBGf.
\end{abstract}

\section{RESUMO}

A maior causa de ondas difratadas na subsuperfície da terra é devido a estruturas complexas (pontiagudas) que apresentam tamanhos das mesma ordem de grandeza do comprimento de onda. Neste trabalho estamos propondo um método de localização de pontos difratores no domínio do tempo baseado nas trajetórias para Continuação do Afastamento(OCO) e no procedimento para migração de afastamento nulo. Este método além de localizar os pontos difratores, também consegue fornecer o modelo de velocidade média com um resultado implícito no processo. Através de uma análise interpretativa entre o painel de coerência de migração e o painel de probabilidade máxima de um evento de difração, este método é capaz de distinguir curvas de difrações originadas de bordas ou pontos de curvas originadas a partir de estruras siclinais, anticlinais e lentes. A viabilidade do nosso método é comprovada através de um conjunto de exemplos numéricos.

\section{ABSTRACT}

A major cause of seismic diffracted waves at subsurface are due unsmooth structures that show sizes in the same order of wavelength. Since the wavefield incident can be meaningfully affected by the these unsmooth structures, many important features can be used to improve imaging practice. In this paper we are proposing a diffraction location method in the time domain based on offset continuation (OCO) trajectories and migration to zero offset (MZO) procedure. This method beyond locating the diffraction points in the time domain it is also capable to provides an average velocity model in the time domain as a implicit result. Performing a interpreta- tive analysis between the coherence migrated panel with highest probability coherence panel the method it is able to distinguish diffraction signatures originated from edges or points to the caustic signatures originated from folded syncline, anticlinal and lenses. The feasibility of our method is verified using a numerical data set examples.

\section{INTRODUCTION}

The potential of seismic diffraction for seismic processing is well-known. Many recent publications make use of diffractions for velocity estimation (Sava et al., 2005; Novais et al., 2008; Landa e Reshef, 2009), hydrocarbon reservoir interpretation (Tsingas et al., 2011) and superresolution (Khaidukov et al., 2004). Even though many studies have been dedicated to investigate the role of diffraction signatures in seismic processing, many challenges still existing and must be overcome. In a review paper, (Moser, 2012) has raised some phenomenological questions related to the traveltime signatures (diffraction curves) and discussed the general relationship between hyperbolic events associated with edges, tips, or pinch-outs and the signature of a syncline folded region, known as caustic diffraction. In the zero-offset or near-offset domain, this bow-tie structure appears to be very similar to a conventional diffraction event originating from a point, tip, or edge.

In this paper, we propose a method to localize diffractions in the time-migrated domain based on offset continuation (OCO) trajectories (Coimbra et al., 2012) and the migration to zero offset (MZO) procedure (Tygel et al., 1998; Bleistein et al., 1999). Migration to zero-offset (MZO) can be understood as combination of migration and demigration (Tygel et al., 1996, 1998) or normal and dip moveout (NMO/DMO) (Bleistein et al., 1999). In the other words, MZO also can be understood as seismic procedure that approximates a seismic zero-offset data set from pre-stack offset data. This operation results in a stacked section with enhanced signal/noise ratio and eliminates the reflection-point smear. Correspondingly, the offset continuation (OCO) operation approximates common-offset data for one offset from those acquired 
using another offset (Bagaini e Spagnolini, 1996; Santos et al., 1997).

Using the OCO approach, our method accomplishes the MZO procedure of diffractions with the OCO operation. In addition to the location of the diffraction points, the method also allows to determine an average timemigration velocity model. Moreover, based on an interpretative comparison of the coherence migrated panel with highest probability coherence panel, the method is able to distinguish diffraction signatures of points or edges from the caustic signatures originationg from folded syncline regions, anticlinal structures, or lenses. The feasibility of our method is verified using a numerical data example.

\section{THEORY}

Recently, (Coimbra et al., 2012) have introduced the concept of OCO trajectories which describe the kinematic behavior of the OCO operation. The OCO trajectory describes kinematic behavior of a seismic event reflected at the same reflection point under variation of half-offset $h$. Our diffraction imaging uses a diffraction-stack-like algorithm to determine the velocity for which the coherence along an OCO trajectory is the highest. An OCO trajectory starting at a zero-offset gather with $h_{0}=0$ is given by

$$
\begin{aligned}
t\left(\xi, h ; \xi_{0}\right)^{2} & =\frac{4 h^{2}}{V^{2}}+\frac{t_{0}\left(\xi_{0}\right)^{2} h^{2}}{h^{2}-\left(\xi-\xi_{0}\right)^{2}} \\
\left(\xi-\xi_{0}\right) & =\frac{2 \phi_{0} h^{2}}{t_{0}+\sqrt{t_{0}^{2}+4 \phi_{0}^{2} h^{2}}},
\end{aligned}
$$

where $t_{0}$ is zero-offset traveltime, $\xi_{0}$ is the midpoint, $\phi_{0}$ is the zero-offset traveltime slope, and $\xi$ and $t$ are the midpoint and traveltime in the common-offset section with half-offset $h$. Equation 1 was derived by (Hubral et al., 1996), and equations 2 is obtained using the envelope condition

$$
\frac{\partial t}{\partial \xi_{0}}=0
$$

Since the zero-offset travel-time can be represented as

$$
t_{0}\left(\xi_{0} ; x, \tau\right)=2 \sqrt{\left(\frac{\tau}{2}\right)^{2}+\left(\frac{x-\xi_{0}}{v}\right)^{2}},
$$

where $\tau$ is the vertical traveltime and $x$ is the horizontal coordinate of the reflection point, slope $\phi_{0}$ is given by

$$
\phi_{0}\left(\xi_{0} ; x, \tau\right)=-2 \frac{\left(x-\xi_{0}\right)}{v^{2} t_{0}\left(\xi_{0}\right)} .
$$

\section{COHERENCE ANALYSIS AND VELOCITY MO- DEL CONSTRUCTION}

For each image point $(\tau, x)$ in the migrated section, our diffraction-imaging algorithm consists of the following steps:

(1) - Determine OCO-trajectory starting points $\left(\xi_{0}, t_{0}\right)$ using equation 4 for a set of trial velocities $v$.

(2) - At each starting point, determine the local event slope using equation 5 .

(3) - For each trial velocity $v$, construct the OCO trajectories for all sets $\left(t_{0}\left(\xi_{0}\right), \phi_{0}\right)$ using equations 1 and 2.

(4) - Collect the data amplitudes along the corresponding OCO trajectories into a panel with axes $\xi$ and $h$, i.e., flatten the surface formed by these OCO trajectories.

(5) - In this panel, calculate the semblance (Neidell e Taner, 1971) for each constant $\xi$ for varying $h$.

(6) - Repeat steps (3) to (5) for all velocities. Select the pair $(\xi, v)$ with the highest coherence and attribute it to point $(\tau, x)$.

\section{APPROXIMATELY HYPERBOLIC EVENTS}

Many approximately hyperbolic events can be mistaken for diffraction events. One famous example is a bowtie signature. Figure 1 schematically illustrates three typical situations that can generate approximately hyperbolic events. As discussed in the Introduction, it is not possible using kinematic zero-offset properties only to distinguish between hyperbolic events originating at points or edges and caustic events or other hyperbolic events from domes or anticlinal structures. However, there are kinematic differences between the offset behavior of such similar events that allow to differentiate between them. Figure 1 discusses these kinematic differences.

Figure 1a depicts the kinematic behavior of an edge diffraction, Figure $1 b$ that of a caustic event originating at a syclinal structure, and Figure $1 c$ that of a quasihyperbolic event originating at an anticlinal reflector. As we can see in Figure 1, the geometric forms of the events in a zero-offset gather are rather similar to each other. However, differences become evident when farther offsets are taken into account. This can be recognized also from the different behavior of the OCO trajectories indicated in Figure 1.

The different behavior of the OCO trajectories can be utilized to distinguish between different types of quasihyperbolic events during the diffraction-imaging procedure. The procedure consists of the following steps:

(1) - For point $(\tau, x)$, trace the traveltime curve (equation 4 ) with the velocity determined using the above algorithm.

(2) - Along this curve, extract the slope curve (equation 5).

(3) - For each point on the traveltime curve, using its respective slope, construct the OCO trajectory (equations 1 and 2).

(4) - Along each OCO trajectory starting at a point 
(a)

(b)

(c)

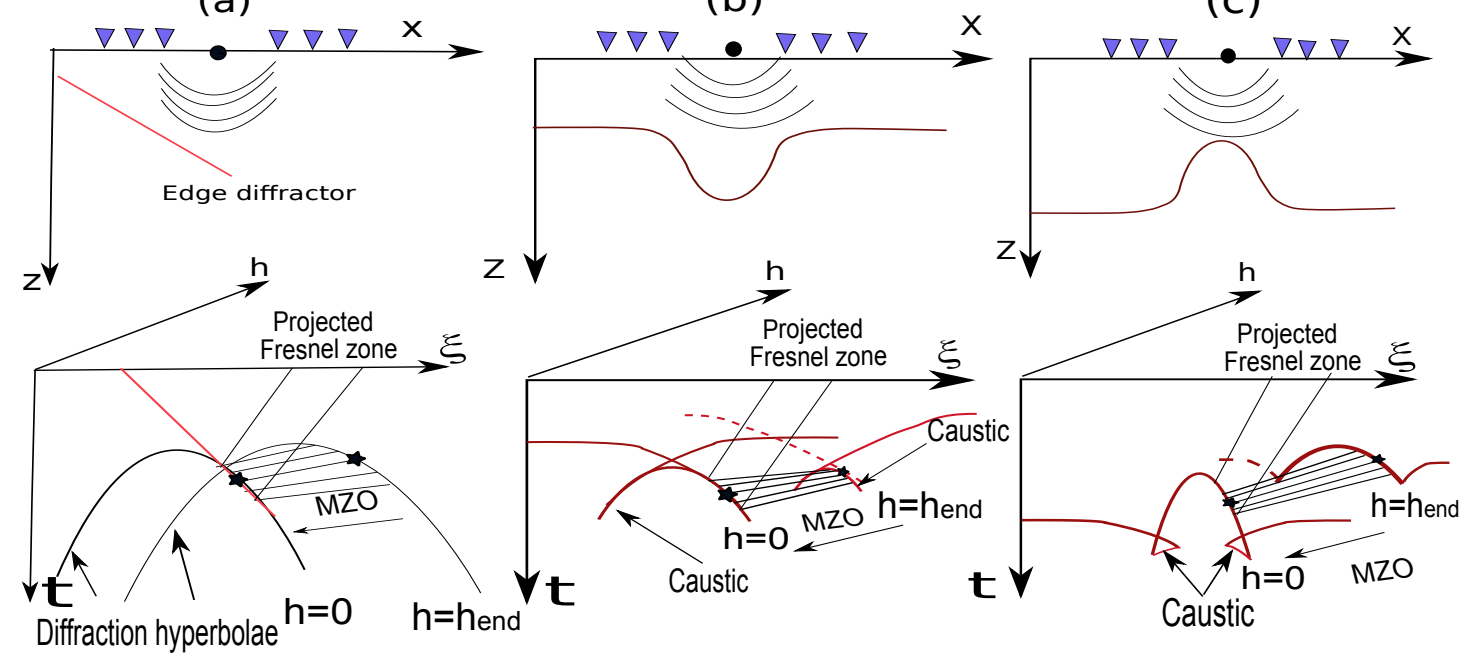

Figura 1: (a) Illustration of the depth model with the edge diffractor (top). The corresponding time section with diffraction signatures in different CO gathers (bottom). (b) Illustration of the depth model for a tightly folded syncline (top). The corresponding time section in different CO gathers and with bow-tie signature associated the folded syncline (bottom).(c) Illustration of an anticlinal structure (top). The corresponding time section in different $\mathrm{CO}$ gathers and with a hyperbolic event like (bottom).

$\left(t_{0}(i), \xi_{0}(i)\right)$, calculate the semblance value $\left.S(i)\right)$.

(5) - For the complete traveltime curve $t_{0}\left(\xi_{0}\right)$, calculate the value $S_{h}=\left(\prod_{i=1}^{N} S(i)\right)^{\frac{1}{N}}$. Then, $S_{h}$ is the hyperbolic coherence, which measures the probability that the event associated with point $(\tau, x)$ is hyperbolic.

In the next section, we demonstrate the capacity of our method to image diffractions and distinguish these types of events.

\section{RESULTS AND DISCUSSIONS}

We firstly tested the feasibility of our method on synthetic data from a simple model with a single interface, exhibiting an an edge diffractor at the shoulder of a synclinal region. The background velocity of this model is $v=3000 \mathrm{~m} / \mathrm{s}$. Figure 2a shows the model with ray tracing trajectories for the zero-offset configuration. Figure $2 b$ shows the same model with rays for a half-offset of $200 \mathrm{~m}$, and Figure 2c shows the rays for a half-offset of $400 \mathrm{~m}$. Note that in Figures $2 \mathrm{~b}$ and Figure $2 \mathrm{~b}$ the caustic it is separating in two focal points. This occurs due the kinematic properties of the caustic event as a function of offset. This effect does not occur in the case of a conventional diffraction originating at a tip or edge.

Using zero-order Kirchhoff modeling, we generated commonoffset gathers with half-offsets ranging from $100 \mathrm{~m}$ to $580 \mathrm{~m}$. Figure $2 \mathrm{~d}$ depicts a section for a half-offset of $200 \mathrm{~m}$. All sections were modeled using 151 shotreceiver pairs at a spacial sampling of $20 \mathrm{~m}$. The source pulse was a Ricker wavelet with dominant frequency of $20 \mathrm{~Hz}$. We added Gaussian noise corresponding to a S/N of about 5 with respect to the reflection event (about 0.5 with respect to the diffraction event).
Applying our method, we first calculate the coherence along the sets of OCO trajectories as described above. The resulting migrated coherence section is depicted in Figure 3a. The form of the reflector is clearly recognizable, together with some uncollapsed artifacts that appear at edge point and in the center of the curved reflector's synclinal part. Figure 3b shows the hyperbolic coherence $S_{h}$ for all points in the migrated section. The two nearly hypberbolic events stand out. Comparing these two events, it is possible distinguish between the different types of geology that generate diffractionlike events.

As a more realistic test, we applied our method to a more complex model, depicted in Figure 4a. This model includes 4 tip diffractors and a dome structure that also generates a hyperbolic event. The velocities range from $1900 \mathrm{~m} / \mathrm{s}$ to $2000 \mathrm{~m} / \mathrm{s}$. As before, we use conventional Kirchhoff modeling to generate the corresponding synthetic dataset. Figure $4 \mathrm{~b}$ depicts a $\mathrm{CO}$ section with $h=100 \mathrm{~m}$. The total coverage consists of $25 \mathrm{CO}$ sections for half-offsets ranging from $100 \mathrm{~m}$ to $580 \mathrm{~m}$. Each CO section contains 151 shot-receiver pairs separated by $20 \mathrm{~m}$. The source pulse is a Ricker wavelet with dominant frequency of $20 \mathrm{~Hz}$. We added Gaussian noise corresponding to a $\mathrm{S} / \mathrm{N}$ of about 5 with respect to the strongest reflection event (about 0.5 with respect to the diffraction events).

Figure 5a shows the migrated coherence section. The aperture used to perform the stack was 100 traces $(2000 \mathrm{~m})$, which aperture corresponds to a maximum dip angle of $70^{\circ}$. As in the simpler model, the model structure is visible (except for the parts of the dome with dips higher than $70^{\circ}$ ). At the tips and the top of the dome, 

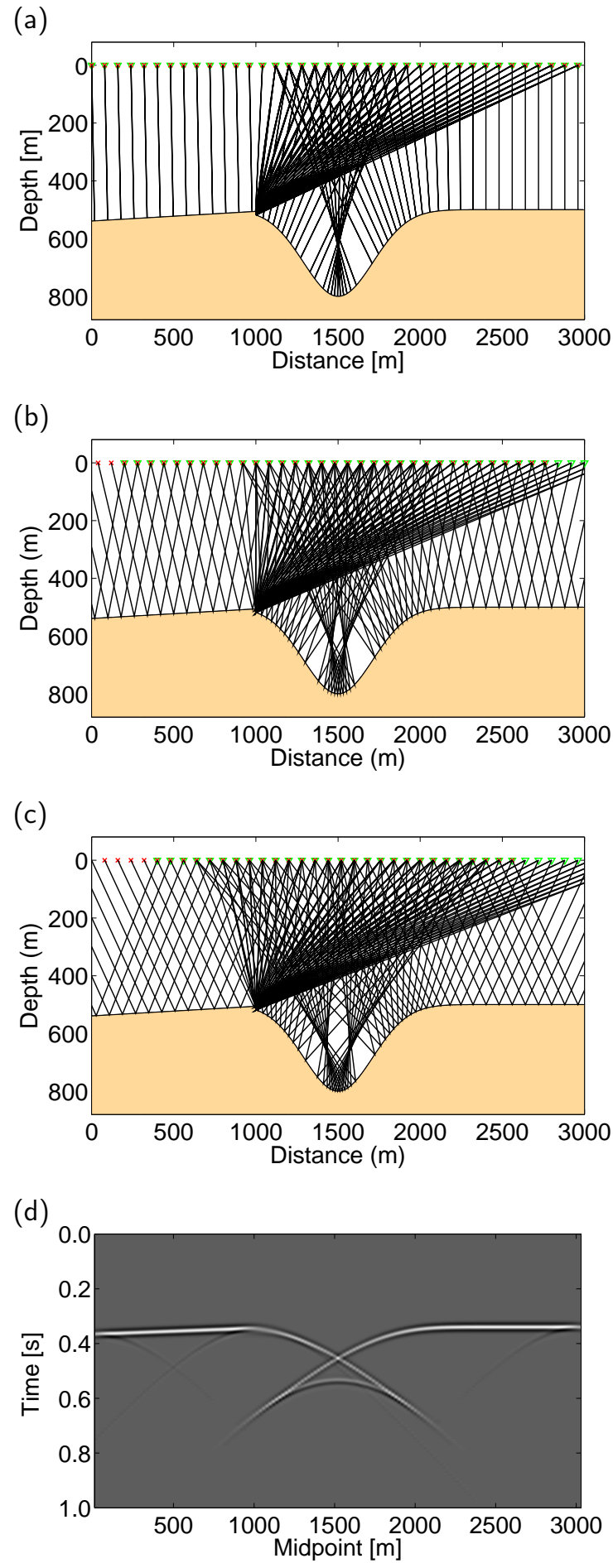

Figura 2: Model with one edge diffractor and a folded synclinal whit a ray tracing for half-offset of (a) 0 , (b) 400 and (c) $800 \mathrm{~m}$. (d) Common-offset section for $h=$ 100.

uncollapsed artifacts indicate the presence of hyperbolic events. Figure 5b shows the hyperbolic coherence panels. Again, the hyperbolic events are collapsed to points. The event at the top of the dome is clearly weaker, indicating that it it was not generated by a diffraction point.

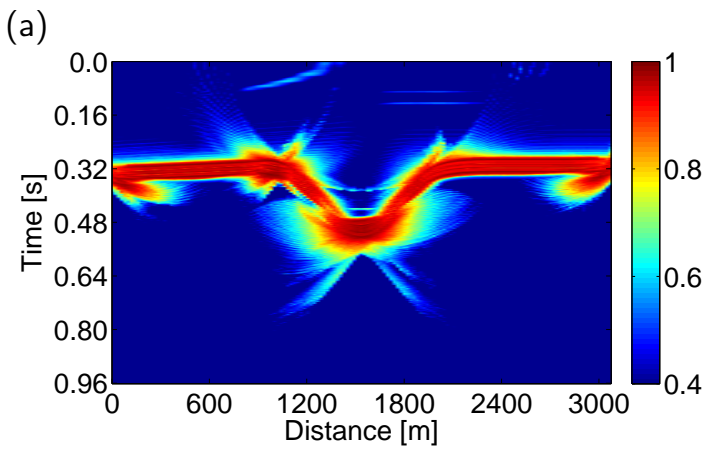

(b)

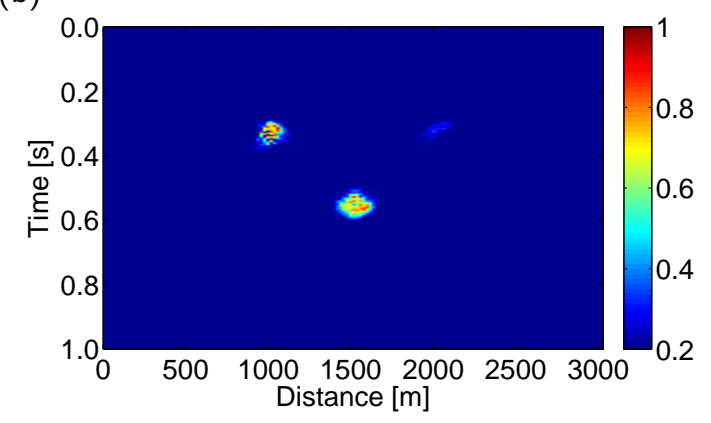

Figura 3: (a) Migrated coherence section. (b) Hyperbolic coherence panels.

(a)

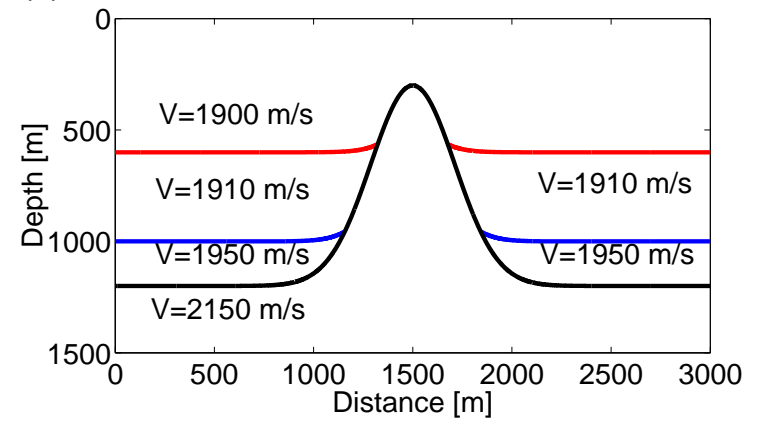

(b)

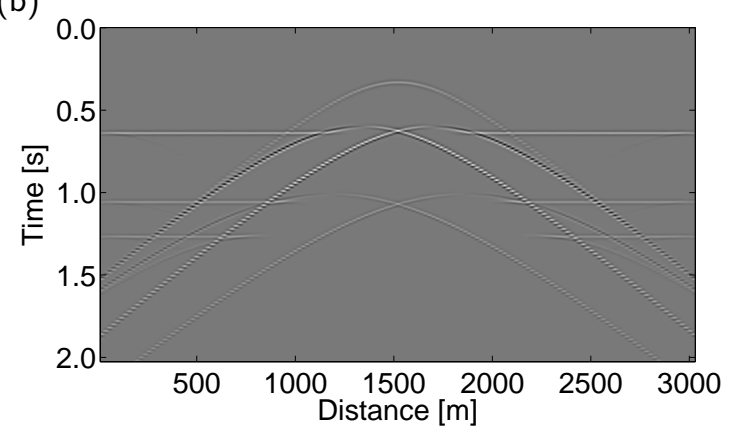

Figura 4: (a) Model with four edge diffractors and a dome structure. (b) Common-offset section for $h=$ 100 .

\section{VELOCITY ESTIMATION}

Figure 6 demonstrates how the OCO trajectories contain velocity information. It depicts the OCO-trajectory panel for an image point located on the image of the 


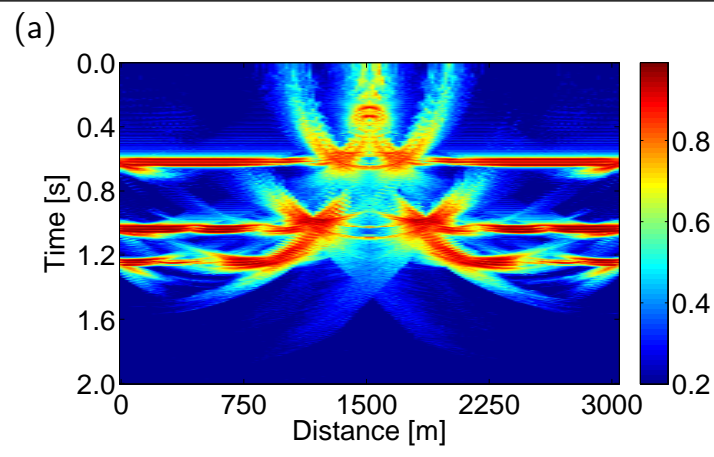

(b)

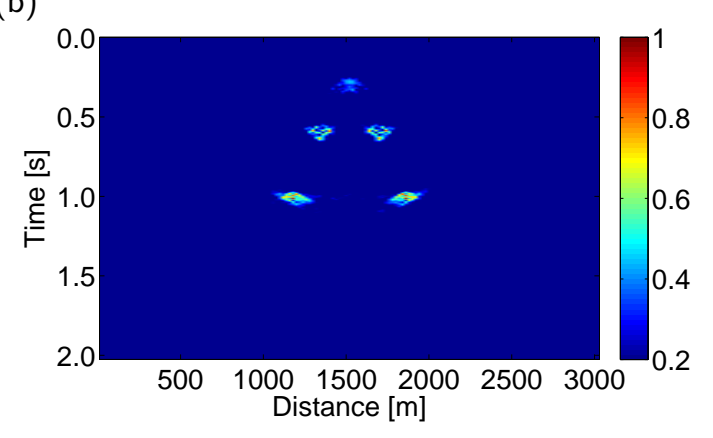

Figura 5: (a) Migrated coherence section. (b) Hyperbolic coherence panel.

top reflector $(x=750 \mathrm{~m}, \tau=0.6 \mathrm{~s})$. For the correct velocity (Figure $6 \mathrm{~b}$ ), high coherence aligns along a horizontal strip. For incorrect velocity, lower coherence produces different patterns. (Figures 6a and c).

For too low velocity (Figure 6a), the diffraction curves, and thus the OCO trajectories, associated with reflection points do not touch the reflection events at far offsets. Thus, only near-offests contribute to the final coherence section. For the correct velocity, the diffraction curves correctly touch the reflection event within the projected Fresnel zone (Hubral et al., 1993; Schleicher et al., 1997) for all offsets. In this way, high coherence aligns horizontally at all offsets, thus contributing to the stack (Figure 6b). For too high velocity, the diffraction curves cross the events. This leads to two tails in the OCOtrajectory panel, also reducing the contribution of far offset to the coherence stack (Figure 6c).

The information contained in the panels of Figure 6 can be used to estimate the size of the tangency region, i.e., the projected Fresnel zone of an image point at the reflection event. In this way, it can be used to improve Fresnel-zone tapers that are used to reduce boundary effects in Kirchhoff migration (Hertweck et al., 2003).

\section{CONCLUSIONS}

In this work we propose a method to locate and image diffraction points, simultaneously estimating associated migration velocities. In a couple of numerical examples, our method was capable of distinguishing between dif- (a)

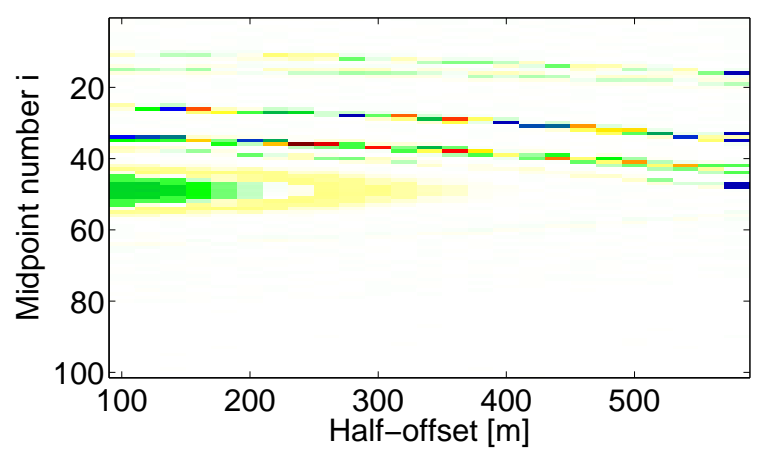

(b)

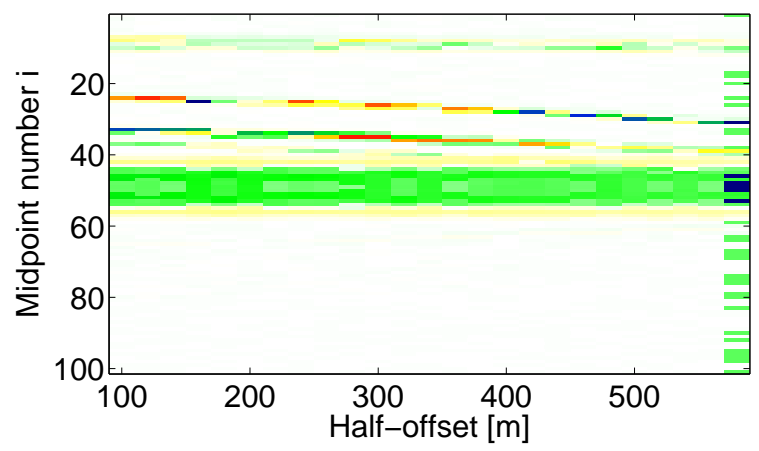

(c)

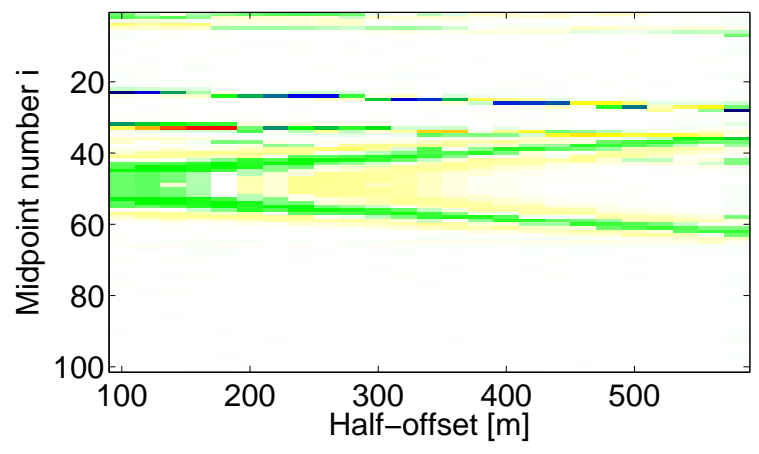

Figura 6: (a) Coherence velocity search panel for a reflector point. (a) Too low velocity of $1700 \mathrm{~m} / \mathrm{s}$, (b) Correct velocity of $1900 \mathrm{~m} / \mathrm{s}$, and (c) To high velocity of $2100 \mathrm{~m} / \mathrm{s}$.

fraction events originating from edge or tip difractors and caustic diffraction events originating from folded synclinal regions or nearly hyperbolical diffraction-like events from dome structures. The method is fully automatic, tracing OCO trajectories that start at the diffraction-traveltime curves in a zero-offset section for trial velocities. Correct velocities lead to horizontally aligned high coherence values, so that subsequent stacks produce a first migrated image. A hyperbolic coherence indicates the probability that a certain event represents a diffraction. However, the techniques allows to extract velocity values also from other diffraction-like events. 
Being based on the same concepts as time migration, the method is applicable wherever the latter produces acceptable images. Since the velocities are extracted as a part of the procedure, the method does not need an a-priori velocity model.

\section{ACKNOWLEDGEMENTS}

This work was kindly supported by the Brazilian agencies CAPES, FINEP, and CNPq, as well as Petrobras and the sponsors of the Wave Inversion Technology (WIT) Consortium.

\section{REFERÊNCIAS}

Bagaini, C., e Spagnolini, U., 1996, 2D continuation operators and their applications: Geophysics, 61, 1846-1858.

Bleistein, N., Cohen, J., e Jaramilo, H., 1999, Trueamplitude transformation to zero offset of data from curved reflectors: Geophysics, , no. 64, 112-129.

Coimbra, T. A., Novais, A., e Schleicher, J., 2012, Offset continuation $(\mathrm{OCO})$ ray tracing using OCO trajectories: Stud. Geophys. Geod, 56, 65-82.

Hertweck, T., Jäger, C., Goertz, A., e Schleicher, J., 2003, Aperture effects in 2.5-D Kirchhoff migration: A geometrical explanation:, 68, 1673-1684.

Hubral, P., Schleicher, J., Tygel, M., e Hanitzsch, C., 1993, Determination of Fresnel zones from traveltime measurements:, 58, no. 5, 703-712.

Hubral, P., Tygel, M., e Schleicher, J., 1996, Seismic image waves: Geoph. J. Int., 125, 431-442.

Khaidukov, V., Landa, E., e Moser, T. J., 2004, Diffraction imaging by focusing-defocusing: An outlook on seismic superresolution: Geophysics, 69, no. 6, 1478-1490.

Landa, E., e Reshef, M., 2009, Separation, imaging, and velocity analysis of seismic diffractions using migrated dip-angle gathers: Separation, imaging, and velocity analysis of seismic diffractions using migrated dip-angle gathers:, 79th Ann. Internat. Meeting, SEG, Expanded Abstracts, 2176-2180.

Moser, T. J., 2012, Review of ray-Born forward modeling for remigration and diffraction analysis: Stud. Geophys. Geod., 56, i-xvii.

Neidell, N., e Taner, M. T., 1971, Semblance and other coherency measures for multichannel data: Geophysics, 36, 482-497.
Novais, A., Costa, J., e Schleicher, J., 2008, GPR velocity determination by image-wave remigration: Journal of Applied Geophysics, 65, 65-72.

Santos, L., Schleicher, J., e Tygel, M., 1997, 2.5-D trueamplitude offset continuation: J. Seism. Expl., 6, no. 2/3, 103-116.

Sava, P., Biondi, B., e Etgen, J., 2005, Wave-equation migration velocity analysis by focusing diffractions and reflections: Geophysics, 70, no. 3, U19-U27.

Schleicher, J., Hubral, P., Tygel, M., e Jaya, M. S., 1997, Minimum apertures and Fresnel zones in migration and demigration:, 62, no. 2, 183-194.

Tsingas, C., Marhfoul, B. E., Satti, S., e Dajani, A., 2011, Diffraction imaging as an interpretation tool: First Break, 29, 57-61.

Tygel, M., Schleicher, J., e Hubral, P., 1996, A unified approach to 3-D seismic reflection imaging, part ii: Theory: Geophysics, 61, no. 3, 759-775.

Tygel, M., Schleicher, J., Hubral, P., e Santos, L., 1998, 2.5-D true-amplitude Kirchhoff migration to zero offset in laterally inhomogeneous media: Geophysics, 63, no. 2, 557-573. 